\title{
Seat Discomfort of Dutch Truck Driver Seat: A Survey Study and Analysis
}

\author{
Chee Fai Tan \\ Department of Industrial Design, Eindhoven University of Technology, the Netherlands. \\ Faculty of Mechanical Engineering, Technical University of Malaysia, Melaka, Malaysia. \\ Wei Chen \& Matthias Rauterberg \\ Department of Industrial Design, Eindhoven University of Technology, the Netherlands.
}

\begin{abstract}
This paper described a survey that was designed to examine the seat discomfort and travel time factors for Dutch truck driver seat to reduce discomfort. Truck drivers were at risk of body discomfort for long hours sitting, and experience significant discomfort at different body parts. For the truck seat questionnaire, 217 Dutch truck drivers completed self administered questionnaires. Statistical methods were applied to analyze the surveys. Body discomfort level after one hour and five hours were studied. The outcomes from the analytical results were important and required more attention to reduce the body discomfort for long hour sitting.
\end{abstract}

\section{INTRODUCTION}

The Cambridge Advanced Learner's Dictionary [1] defines comfort as a pleasant feeling of being relaxed and free from pain. Comfort is defined as absence of discomfort [2]. The term "seat comfort" is typically is used to define the short-term effect of a seat to the human body. Comfort is a generic and subjective feeling that is difficult to measure, interpret, and related to human physiological homeostasis and psychological well being [3]. Generally, comfort issues, which are not under debate by researchers are [4]: (1) comfort is a construct of a subjectively-defined personal nature; (2) comfort is affected by factors of various nature (physical, physiological, psychological); and (3) comfort is a reaction to the environment.

Today, comfort is an attribute which has increased demand from the drivers. The driver comfort is depends on different features and environment during the driving. Seat comfort is a very subjective issue because it is the final determination of the customer and evaluations are based on their opinions having experienced the seat [5]. One of the products often considered in truck industry is the driver's seat. The truck driver's seat has an important role to play in fulfilling driver comfort expectations. The seat is one of the important features of vehicle and this is the place where the truck driver spends most of their time.

According to the 'European Union Legislation for Drivers and Promote' [6], the weekly driving time for truck drivers shall not exceed 56 hours. Commercial trucks are unique in that they are specifically designed to transport heavy loads over long distances, where for the trucks; high priority has been given to durability and functional efficiency. On the contrary, automobiles are made to comfortably accommodate passengers over relatively shorter distances [16]. The personal vehicles are emphasized in the factors such as riding comfort,

Page 1 of 8 
handling, technology and appearance are of high importance in vehicle market. The different requirements of commercial trucks and personal automobiles have led to separate directions in design. The truck driver's seat, which is in contact with the drivers, plays an important role to position the driver to perform the task of driving, meet the safety requirements, and be acceptable to the driver's comfort needs. Therefore the truck driver's seat plays an important role to position the driver to perform the task of driving, meet the safety requirements, and address the driver's comfort needs.

The body discomfort feeling for truck drivers increased after 5 hours of travel. The findings showed that buttock, shoulder and neck were the top three most uncomfortable body parts for truck driver over time. The survey set out to examine the relationship between body part discomforts for commercial truck driver to prioritize action aimed at discomfort reduction.

\section{METHOD}

\section{QUESTIONNAIRE DEVELOPMENT}

The purpose of the questionnaire is to determine the body back discomfort level of truck driver for the designed of new truck driver seat. The questionnaire consisted of two sections: (1) question regarding comfort levels of each part of their body back after one hour and five hours travel; (2) question about demographic background. The questionnaire begins with a short, self-explanatory introduction in which the purpose and background of the survey was explained; it also was emphasized that data would be treated with confidentiality and analyzed in an anonymous manner.

The primary means of investigation is to identify the body back discomfort level over time during truck driving. This was devised to identify the body back part discomfort, and indicate the discomfort level for each defined body back part for after one hour and after five hours. In order to identify the body back part discomfort level, a body mapping method is used. In this method, the perception of discomfort is referred to a defined part of the body back. The subject is asked for the discomfort experiences during flight for each defined body back part, and to assess the discomfort level using a five point Likert scale. The scales are graded from 'extreme discomfort' to 'normal'. Figure 1 shows the body back map and scales for discomfort assessment.

\section{QUESTIONNAIRE ADMINISTRATION}

For the truck seat discomfort questionnaire, the content of the questionnaire was discussed and approved by BGZ Wegvervoer (Road transport), an intermediary organization which is dedicated improving working conditions, and create better health policies in road transport companies in the Netherlands. Due to the confidentiality of the BGZ Wegvervoer member database, 1000 questionnaires were distributed through BGZ Wegvervoer with returned post attached. A total of 217 questionnaires were returned by post. The questionnaire took between five to six minutes for completion. The data collection took place from June to July 2008. All data from truck seat discomfort questionnaire were analyzed using the statistical program SPSS 16.0. 


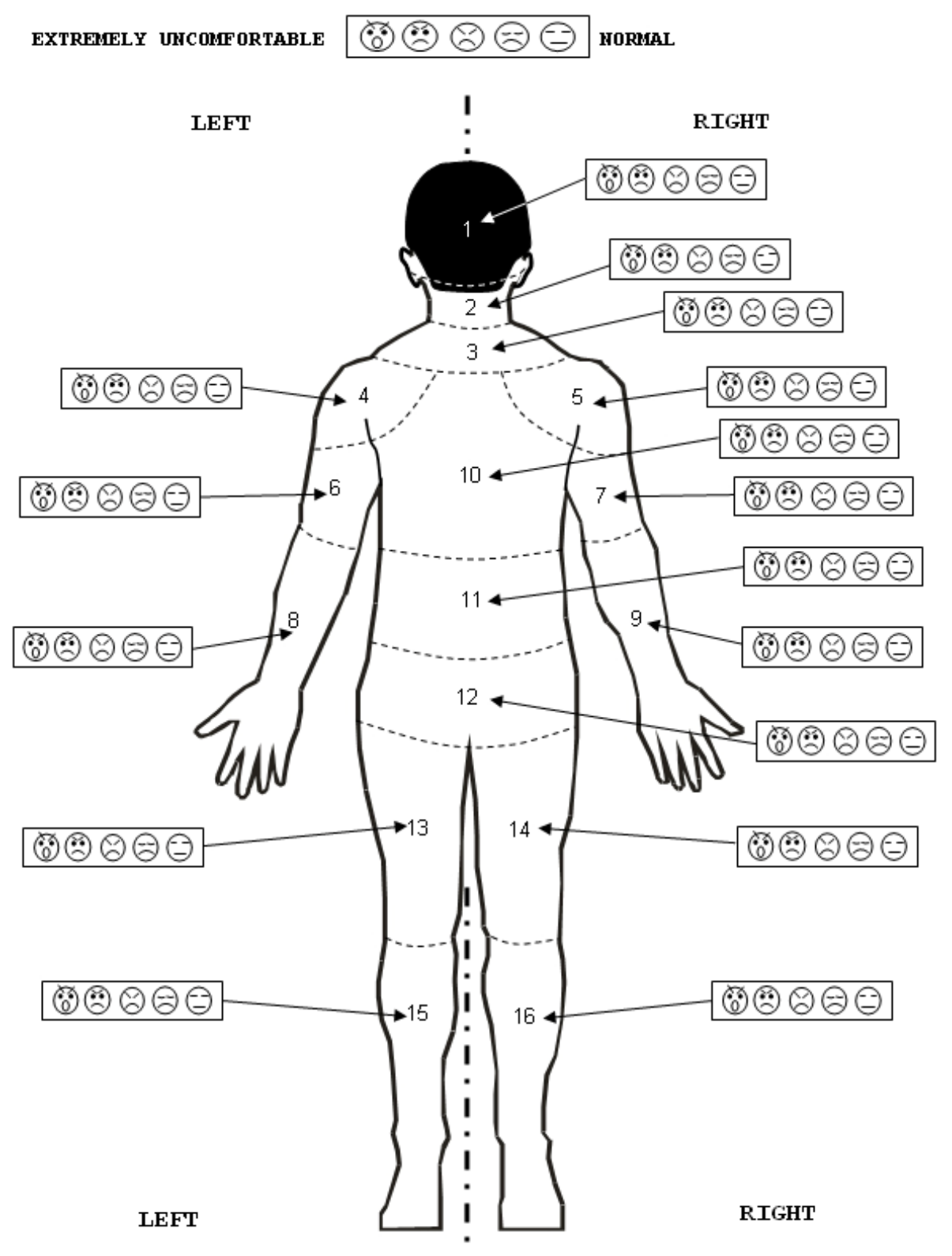

Figure 1: Body back map and scales for body discomfort evaluation

\section{RESULTS}

\section{DEMOGRAPHICS}

The truck driver seat group consisted of 215 individuals (211 male and 4 female). The average age of the truck drivers was 45.6 years old, the average weight was 92.6 kilograms and the average height was $1.81 \mathrm{~m}$. The average body mass index (BMI) of the truck drivers was $28.32 \mathrm{~kg} / \mathrm{m} 2$. Table 1 shows the demographic details for truck driver. 
Table 1: Demographic details for truck driver

\begin{tabular}{|l|l|l|l|}
\hline Variable & Range & Mean & Standard Deviation \\
\hline Age (years) & $19-69$ & 45.6 & 10.6 \\
\hline Weight $(\mathrm{kg})$ & $60-165$ & 92.6 & 17.4 \\
\hline Height $(\mathrm{m})$ & $1.58-2.11$ & 1.81 & 8.2 \\
\hline BMI $(\mathrm{kg} / \mathrm{m} 2)$ & $19-43$ & 28.32 & 4.7 \\
\hline
\end{tabular}

\section{BODY BACK PART DISCOMFORT LEVEL}

The objective of the study is to have better understanding of the discomfort level to different parts of the body, and their correlations to travel duration and demographics details. From the statistical analysis, there is no significant relationship between gender and body discomfort could be determined, due to small female sample size in the survey. There was a significant relationship between age and right shoulder discomfort after one hour travel (Pearson's $r=.139, \mathrm{p}<.05$, two tailed). In general, older truck driver felt more discomfort on their right shoulder after 1 hour travel than younger truck drivers. Height was negatively correlated with head discomfort (Pearson's $r=-.161, p<.05$, two tailed) and neck discomfort (Pearson's $r=-.139 p<.05$, two tailed) after one hour travel, with the taller drivers tending to feel less comfortable. The taller truck driver felt less discomfort at head and neck after 1 hour travel than shorter truck driver.

For the differences between weight and body back discomfort, the correlation showed that there was a significant relationship between weight with neck discomfort (Pearson's $\mathrm{r}=-.171, \mathrm{p}<.05$, two tailed) and shoulder discomfort (Pearson's $r=-.145, \mathrm{p}<.05$, two tailed) after one hour travel. Subsequently, it was discovered that BMI was correlated with right lower leg discomfort after 1 hour travel (Pearson's $r=-.138, p$ $<.05$, two tailed). It was indicated that truck driver with higher BMI tended to feel more discomfort at right lower leg after one hour travel.

For after five hours of travel, there was no significant correlation between body discomfort and age, height, weight as well as BMI.

Univariate analysis of variance was conducted to find out the differences of body back discomfort level for truck driver between after one hour and after five hours travel. Figure 2 shows the comparison of body discomfort level for different body back part after one hour and after five hours travel. Most of the respondents felt that buttock was the most discomfort body back part than others body back part after one hour travel $(\mathrm{M}=$ $1.24, \mathrm{SD}=1.34)$ as well as after five hours travel $(\mathrm{M}=1.68, \mathrm{SD}=1.43)$. It was followed by lower back, neck, shoulder and right upper leg. From Figure 2, it shows that there is the same top five body back part discomfort after one hour travel and after five hours travel. The results also showed that the body back discomforts level after five hours travel was higher than after one hour travel.

As shown in Figure 2, there are different levels of body back discomfort for truck driver after one hour travel. The most uncomfortable body part for truck drivers is the buttock area; it is followed by lower back, neck, shoulder, left upper leg and right upper leg. The discomfort level increases after five hours travel. The most 
uncomfortable body part for truck driver is also at the buttock area; it is followed by lower back, neck, shoulder and right upper leg.

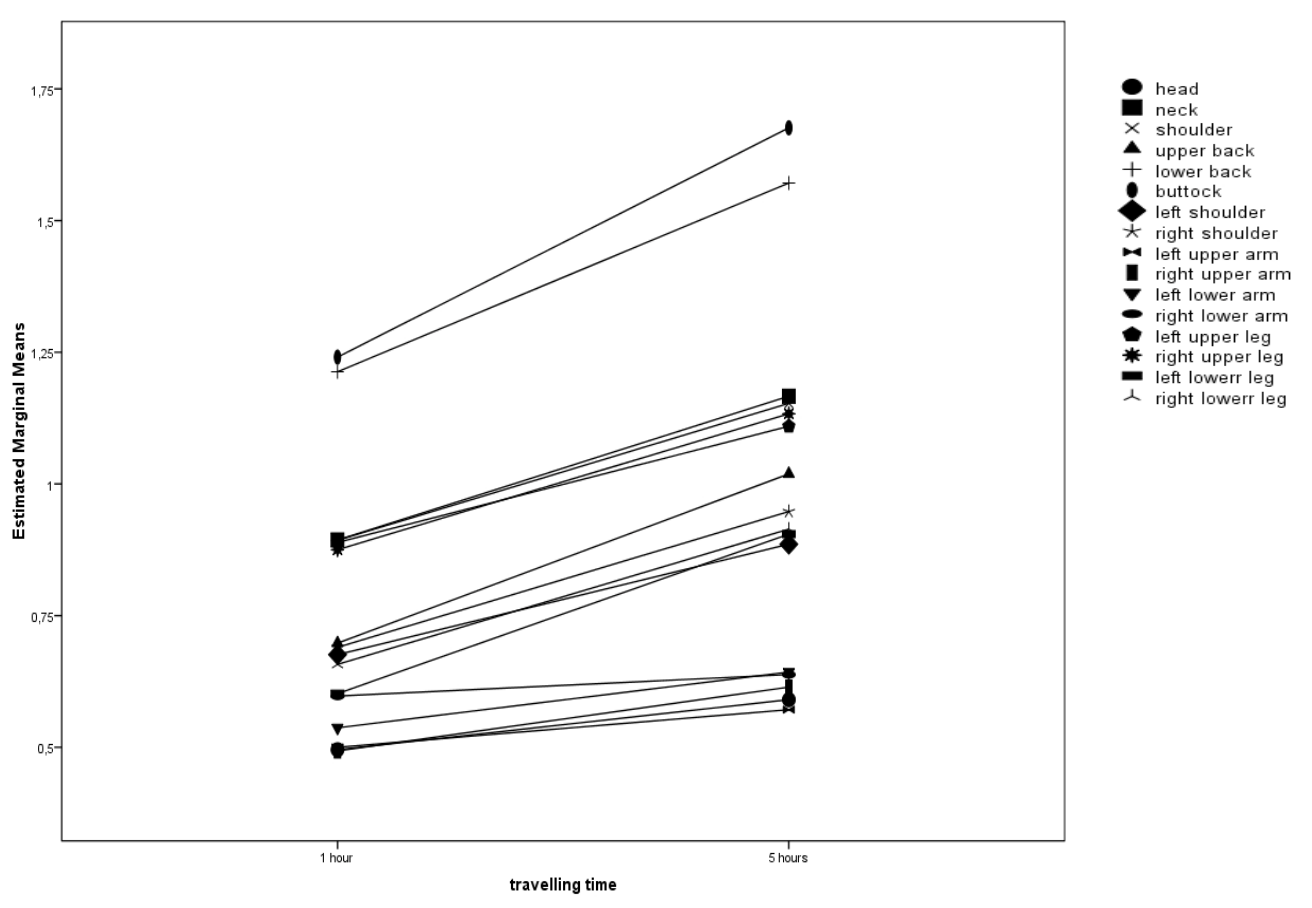

Figure 2: Body back discomfort of truck driver over one hour and five hours travel

The nonparametric test, namely, Friedman test was used to test the null hypothesis that the sixteen related variables come from the same population. For each body part, the sixteen body discomfort levels are ranked from one to sixteen. The test statistic is based on these ranks. The asymptotic significance of $p<0.001$ indicates that there is a significant overall difference among the sixteen mean ranks for body discomfort level after one hour and after five hours travel. Figure 3 showed average ranks for the body part discomfort groups after one hour and after five hours travel.

As refer to Figure 3, from the result of body discomfort after one hour travel, it showed that buttock $(\mathrm{M}=2.24$, $\mathrm{SD}=1.34)$ exhibited the highest discomfort level among others. It was followed by lower back $(\mathrm{M}=2.21, \mathrm{SD}=$ $1.37)$ and Shoulder $(\mathrm{M}=1.89, \mathrm{SD}=1.17)$. For the body discomfort level after five hours travel, the result showed that buttock $(\mathrm{M}=2.68, \mathrm{SD}=1.43)$ is ranked as the highest discomfort level. It was followed by lower back $(\mathrm{M}=2.57, \mathrm{SD}=1.43)$ and neck $(\mathrm{M}=2.17, \mathrm{SD}=1.26)$. 


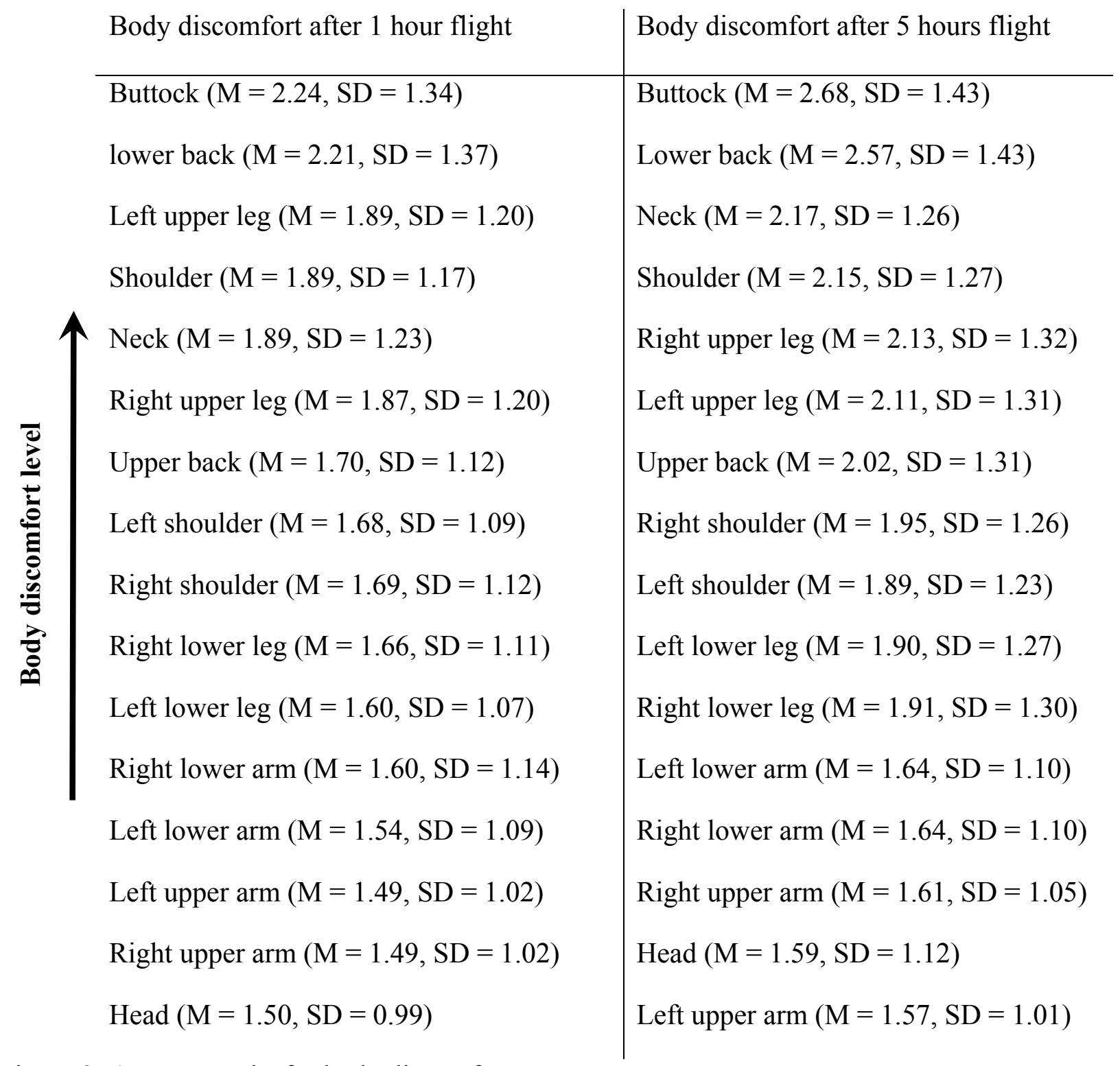

Figure 3: Average ranks for body discomfort

The causes for the uncomfortable can be explained as follows and supported by previous studies. The truck driver requires sitting for long periods of time. The extended period of sitting includes higher risk of back problems, numbness and discomfort in the buttocks due to surface pressure under the thighs [9]. Hulshof and van Zanten [10] reported that truck drivers are exposed to whole body vibration while driving for some periods of time and this has been causing low back pain. Poor posture in some types of truck have been linked with neck and trunk discomfort [11]. In the study of Porter et al. [12], it was observed that buttock discomfort is increased over time. The prolonged sitting and uneven pressure distribution at the buttock may cause the discomfort for truck driver. In the study by Chow and Odell [13] reported that a sitting person unconsciously adjusts his body position when he feels discomfort. There is an inverse relationship between the tolerable pressure levels and the time duration of the pressure. This time pressure relationship depends on many factors such as general health of the people, the diet, seat pan and backrest cushion type etc. If pressure is relieved intermittently, higher pressure can be tolerated for the same time period or a longer duration of a specific pressure. Thus, it will increase the incidence of pressure sores and lengthens the tolerable time period in a given body position.

Page 6 of 8 


\section{CONCLUSION}

In this study, the aim is to gain more insights into truck driver body back discomfort level after one hour and five hours of travel. The demographic background of the respondents such as gender, age, weight and height is taken into consideration for analysis. There were 217 truck drivers completed a questionnaire regarding body discomfort after one hour and after five hours travel. The truck seat discomfort is associated with travel duration. The analytical results showed that buttock is the most uncomfortable body part for truck driver over time. It was followed by lower back and neck. This study can contribute to seat design or uncomfortable reduction strategy for truck drivers

\section{REFERENCES}

1. The Cambridge Advanced Learner's, 3rd edition, Cambridge University Press, 2008.

2. H.T.E. Hertzberg (1972). The human buttocks in sitting: pressures, patterns, and palliatives. SAE Technical Paper, no. 72005.

3. W. Shen, K.C. Parsons, (1997). Validity and reliability of rating scales for seated pressure discomfort. International Journal of Industrial Ergonomics, vol. 20, 441-461.

4. M.P. De Looze, L.F.M. Kuijt Evers, J. V. Dieen (2003). Sitting comfort and discomfort and the relationship with objective measures. Ergonomics, vol. 46, no. 10, 985-997.

5. V.A. Runkle (1994). Benchmarking Seat Comfort. SAE Technical Paper, no. 940217.

6. http://www.euractiv.com / en/ transport/ drivers- deplore-inconsistent-eu-working-time-laws/ article166879. Accessed on 10 November 2007.

7. C. Quigley, D. Southall, M. Freer, A. Moody, M. Porter. Anthropometric Study to Update Minimum Aircraft Seating Standards, presented at EC1270, ICE Ergonomics Ltd., 2001.

8. H. Hinninghofen, P. Enck (2006). Passenger Well-being in Airplanes. Auton Neurosci, vol. 129, no. 1-2, 80-85.

9. W.F. Floyd, D.F. Roberts (1958). Anatomical and Physiological Principles in Chair and Table Design. Ergonomics, vol. 2, 1-16.

10. C. Hulshof, B.V. van Zanten (1997). Whole-body Vibration and Low Back Pain- a Review of Epidemiological Studies. International Archives of Occupational Health, vol. 59, 205-220.

11. M. Massaccesi, A. Pagnotta, A. Soccetti, M. Masali, C. Masiero, F. Greco (2003). Investigation of workrelated disorders in truck drivers using RULA method. Applied Ergonomics, vol. 34, 303-307.

12. J. Mark Porter, D.E. Gyi, H.A. Tait, (2003). Interface Pressure Data and the Prediction of Driver Discomfort in Road Trials, Applied Ergonomics, vol. 34, 207-214.

13. W.W. Chow, E.I Odell (1978). Deformations and Stresses in Soft Body Tissues of a Sitting Person. Journal of Biomechanical Engineering, vol. 100, 79-87.

14. H. Hinninghofen, P. Enck (2006). Review: Passenger Well-being in Airplanes. Autonomic Neuroscience: Basic and Clinical, vol. 129, 80-85.

15. ANON (1999). Which airline? Holiday Which? Spring 1999, 80-83.

16. M. Ahmadian, M.Seigler, D. Clapper and A. Sprouse (2002). A comparative analysis of air-inflated and foam seat cushions for truck seats. Society of Automotive Engineers Technical Paper, Document no. 200201-3108. 


\section{CONTACT INFORMATION}

CheeFai Tan

Designed Intelligence Group

Department of Industrial Design

Technical University Eindhoven

Den Dolech 2, Eindhoven, the Netherlands.

E-mail: c.f.tan@tue.nl

\section{ACKNOWLEDGEMENTS}

The survey was funded by Designed Intelligence Group, Department of Industrial Design, Eindhoven University of Technology and Technical University of Malaysia Melaka. Special thank to Marinka de Groot from BGZ Wegvervoer, the Netherlands for the support. 